\title{
Photoanthropometric Auricular Morphology for Identification in Southeast Nigerians
}

\author{
Onyinye Mary Ozioko ${ }^{1}$, O.A. Egwu ${ }^{2}$, Uche Sebastine Ozioko ${ }^{3}$ \\ ${ }^{1}$ Department of Anatomy, College of Medicine, Enugu State University of Science and Technology \\ ${ }^{2}$ Department of Anatomy, Alex Ekwueme Federal University of Ndufu Alike (FUNAI) \\ ${ }^{3}$ Department of Anatomy, College of Medicine, Enugu State University of Science and Technology \\ Nigeria
}

\begin{abstract}
Auricular anthropometric parameters are useful for facial identification and reconstructive auricular intervention. This study was aimed at assessing, sexual dimorphism in auricular anthropometric parameters. Method: 514 subjects (16-30 years) comprising 258 males and 256 females were selected using simple random sampling technique. Total ear length (TEL), Total ear width (TEW), Total lobe width (TLW), Total lobular height (TLH) at 90o, 45o left and 45o right were measured and analyzed. Results: Males were observed to have higher TEL, TEW parameters than females at all angles, Females were also observed to have a longer TLH than males at 90o, 45o left and 45o right for both sides of the ear: All measured parameters in both sex showed higher values on the right side than the left, right lobular index was also found to be statistically higher $(P<0.05)$ when compared to the left one Conclusion: TEL and TEW measured from all angle are correlated and can be used to determine sex. It can also aid biological profiling, facial recognition from security cameras, planning of cosmetic surgery and product design for specific consumer auricular requirements.
\end{abstract}

\section{Introduction}

Photogrammetry has been introduced as an alternative to direct measurements to obtain angular anthropometric facial landmarks [1]. The outer ear as a biometric characteristic has long been recognized as a valuable means of facial identification by criminal investigators. Investigators frequently have to work with half profile or profile views where the face is partly or fully occluded. In such scenarios, ear recognition can be a valuable amendment to existing facial recognition systems for identifying suspects [2] in smart surveillance tasks and forensic image analysis.

Observed differences in individual auricuar physiognomy has led to the reading of earprints, a fact not generally known amongst ENT-specialists [3]. This highly specialized knowledge has been developed within a branch of forensic medicine and criminology, known as 'earology' or 'otomorphology' [3]. Quantitative descriptive studies of human ear morphology during normal adolescent and adult growth, [4] have shown that the external ear dimensions is sexually dimorphic, hence, knowledge of auricular dimensions is important in understanding the physiognomy and aesthetics of the human body, [5] as well as for determining levels of genetic and environmental control of auricular development [6].

In Nigeria, anthropometric studies have been carried out on variations in auricular morphology in relation to age, sex and ethnicity. Akpa [5] reported ear parameters in Igbos using flexible measuring tapes and calipers [7] reported ear parameters in Adult Nigerians resident in Maiduguri Metropolis using standard vernier caliper [8] carried out a study on morphological changes of the human pinna in relation to age and gender of Urhobo people in southern Nigeria using digital venier caliper.

Despite the numerous reports on ear anthropometry, very few studies in the Sub-Saharan Africa including Nigeria has explored the efficiency of photoanalysis and software technology in the assessment of external ear with the aim of individualization and human identification at a large scale. Therefore, this study therefore aspires to study the auricular dimensions, comparing between Sexes and various age groups for forensic and aesthetic purposes in southeast Nigerians.

\section{Materials and Methods}

A total of 514 subjects were recruited for the study. Age of subjects ranged from 16-30 years because crime tends to peak in adolescence or early adulthood [9]. The subjects were selected using stratified random sampling technique. None of the subjects had previous plastic surgery or trauma on the face. The Ethical approval was obtained from the Ethical Review Committee for Human Experimentation, College of Medicine Enugu State University of Science and Technology, Enugu Nigeria (ESUTHP/CMAC/RA/034/183).

\section{Protocol of Procedure}

Consent was taken from each participant after explaining the purpose of study in accordance with World Medical Association Declaration of Helinski Ethical Principles for Medical Research Involving Human Subjects [10]. 


\subsection{Pre-Image Acquisition}

Before photography was taken, Subjects were numbered using self-adhesive stickers of known length $(45 \times 13 \mathrm{~mm})$ at the sides of the face. Subjects' age, height, weight, sex and state of origin were recorded along with their identification numbers.

Female subjects were asked to clip back hair using hair clips to prevent it from obscuring the photograph of the ear. The tripod was adjusted so that it was equal with the height of the ear of the subject to ensure the ear was visible within the shots.

\subsection{Image Acquisition}

Images were acquired using Nikon D9O digital single lens reflex camera (manufactured by Nikon Corporation Tokyo, Japan) in the same lightening conditions with no illumination changes. Camera settings of 12.3 mega pixel, 600Dpi resolution, fixed local length 90 to $150 \mathrm{~mm}$, high quality macro lens (which assures maximum depth of field) high aperture setting $(\mathrm{f}>16)$ and short exposure time $(>125$ milli sec) were also kept constant.

- Each subject was asked to relax with both hands hanging beside the trunk.

- Subjects were positioned on a line marked $100 \mathrm{~cm}$ from the camera [11]

Camera was moved to either side to have photo taken at $90^{\circ}, 45^{\circ}$ angles parallel to the subject to reduce possibility of Image perspective distortion due to poor positioning.

\subsection{Image Processing}

- When photos had been taken, they were downloaded into Adobe illustrator version 17. (Adobe systems USA)

- All photos were cropped and sharpened if necessary, for a clear picture. They were converted to gray scale (color removed) and contrast increased for the best possible definition. It was necessary for all photographs to be on the same scale for accuracy in measurement.

- Photographs with incorrect lightening or with unnoticed hairs concealing actual auricle dimensions were discarded.

- Image editing software (Image J 1.48 software j (v.j.48 ava 1.6.0 2064 bits written by Wayne Rasband, National institute of mental health, Bethsda, Mary land, USA) process image option was used to process the images.

\subsection{Ear Measurements Taken}

Landmarks were tagged on photograph of the subjects' ear and then measurements were taken and results were given to 2 decimal places.
Total Ear Length: Measurement of the distance between the most superior point of the ear or pinna and the most inferior point of the earlobe (see Figure 1).

Total Ear Width: Measurement of the distance between the most anterior point and the most posterior point of the pinna (Figure 1).

Total Lobular Height: Measurement of the distance between the intertragic notch and the most inferior point of the ear lobule (see Figure 1).

Total Lobular Width: Measurement of the distance between the most anterior point and the most posterior point of the ear lobule (see Figure 1).

The ear landmarks used in this study are: $A G=$ Total Ear length; $\mathrm{CD}=$ Total Ear width; $\mathrm{GE}=$ Total Lobular height; FE = Total Lobular width

Height (stature): Each subject was made to stand erect and height was measured using a stadiometer. Weight: The subjects were asked to remove excess materials like shoes, belt, watch, etc. and the weight of each subject was checked using weighing scale.

Ear index: was calculated as Ear width X 100 [12] Ear length

Lobular index: was calculated as Lobule width $\mathrm{x}$ 100

Lobule length: Age of participants was obtained from self-reported date of birth [13].

\section{Statistical Analysis}

Images was analyzed using pro image $\mathbf{J}$ analyzer and the data obtained was presented in tables and subjected to statistical analysis by using t- test (independent and sample t-test) for the comparison of measurements taken from right and left ears between both sexes, Pearson correlation was used to establish the relationship between known anthropometric variables (Age, Height and Weight) and ear parameters measured with the aid of statistical package for social Sciences (SPSS) IBM version 20. $\mathrm{P}<0.05$ was considered statistically significant and the Mean and standard deviation was calculated for all the parameters.

\section{Results}

This study provides valuable data pertaining to the ear morphology and their different parameters in south east Nigerians. There are 514 subjects (males and females) in our cohorts.

Age and gender of participants in this study are almost pair-matched $(\mathrm{P}>0.05)$ and the male/ female ratio is 1:1.Age distribution of participants showed that majority of population belong to Age group 19-21 while the less frequent age range was from 28-30 age group. 


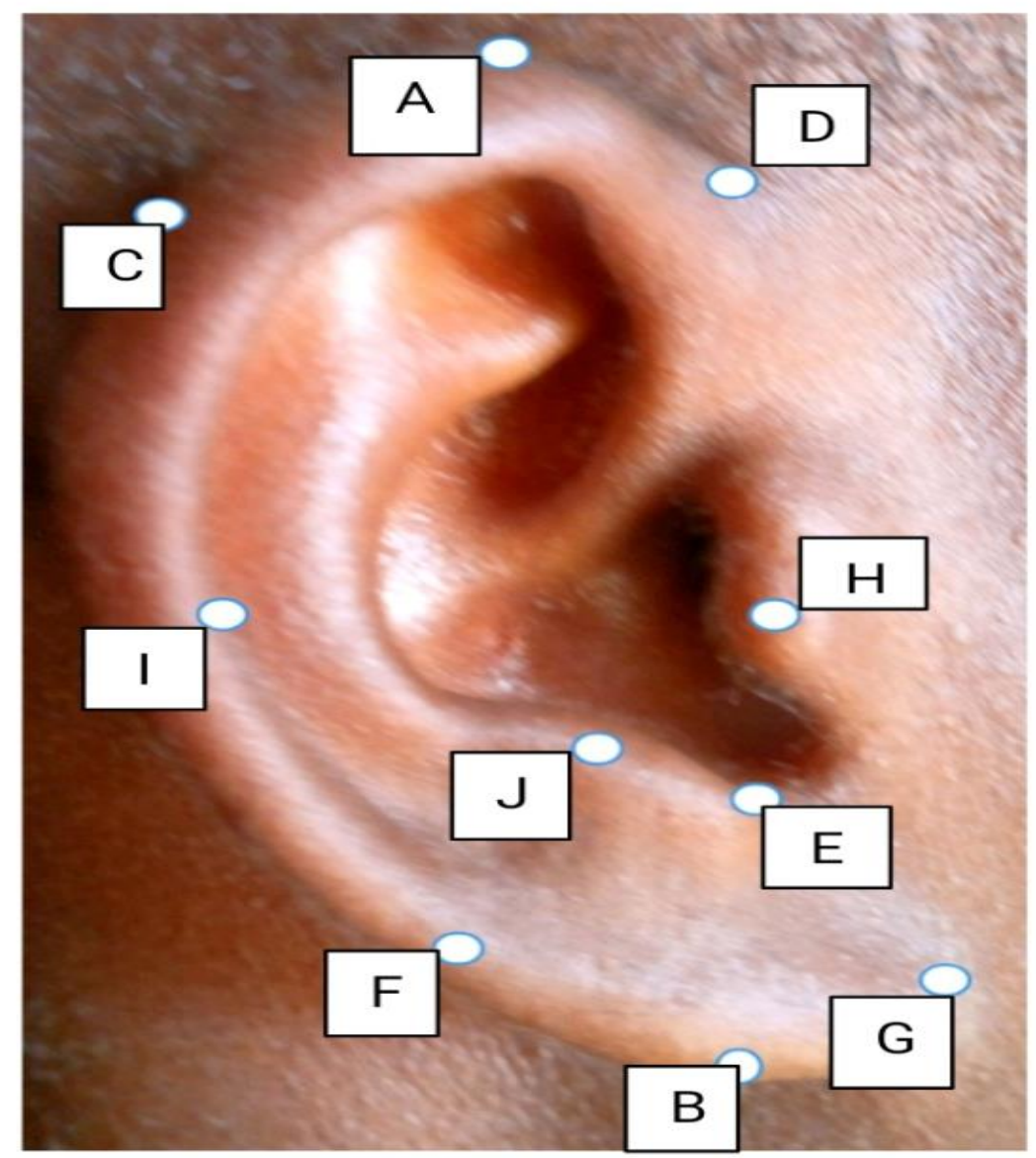

Figure 1. Auricular landmarks

Table 1. Distribution of Age and Sex in the Study

\begin{tabular}{|c|c|c|c|c|c|c|c|c|}
\hline \multirow[t]{2}{*}{ Sex } & \multicolumn{5}{|c|}{ Age group (years) } & \multirow[t]{2}{*}{ Total } & \multirow[t]{2}{*}{$x^{2}$} & \multirow[t]{2}{*}{ P-value } \\
\hline & $16-18$ & $19-21$ & 22-24 & 25-27 & 28-30 & & & \\
\hline Female & 21 & 104 & 83 & 35 & 13 & 256 & \multirow{3}{*}{\multicolumn{2}{|c|}{0.2010 .995}} \\
\hline Male & 19 & 103 & 86 & 36 & 14 & 258 & & \\
\hline Total & 40 & 207 & 169 & 71 & 27 & 514 & & \\
\hline
\end{tabular}

Table 2. Descriptive Statistics Of Measured Parameters Across Cohort In Relation To Sex

\begin{tabular}{|c|c|c|c|c|c|}
\hline Parameter & Side & Angle & Sex & Mean \pm SD & $\mathrm{P}$-value \\
\hline \multirow[t]{12}{*}{ TEL } & \multirow[t]{2}{*}{ Left ear } & $90^{\circ}$ & Male & $6.00 \pm 0.50$ & $0.000 *$ \\
\hline & & & Female & $5.82 \pm 0.49$ & \\
\hline & \multirow[t]{2}{*}{ Right ear } & $90^{\circ}$ & Male & $5.96 \pm 0.48$ & $0.013 *$ \\
\hline & & & Female & $5.85 \pm 0.49$ & \\
\hline & \multirow[t]{2}{*}{ Left ear } & $45^{\circ}$ Left & Male & $6.14 \pm 0.58$ & $0.000 *$ \\
\hline & & & Female & $5.94 \pm 0.51$ & \\
\hline & \multirow[t]{2}{*}{ Right ear } & $45^{\circ}$ Left & Male & $6.15 \pm 0.58$ & $0.007 *$ \\
\hline & & & Female & $6.01 \pm 0.57$ & \\
\hline & \multirow[t]{2}{*}{ Left ear } & $45^{\circ}$ Right & Male & $6.06 \pm 0.50$ & $0.000 *$ \\
\hline & & & Female & $5.88 \pm 0.48$ & \\
\hline & \multirow[t]{2}{*}{ Right ear } & $45^{\circ}$ Right & Male & $6.05 \pm 0.54$ & $0.001 *$ \\
\hline & & & Female & $5.90 \pm 0.49$ & \\
\hline \multirow[t]{7}{*}{ TEW } & \multirow[t]{2}{*}{ Left ear } & \multirow[t]{2}{*}{$90^{\circ}$} & Male & $3.50 \pm 0.37$ & $0.003 *$ \\
\hline & & & Female & $3.41 \pm 0.33$ & \\
\hline & \multirow[t]{2}{*}{ Right ear } & \multirow[t]{2}{*}{$90^{\circ}$} & Male & $3.49 \pm 0.39$ & $0.029 *$ \\
\hline & & & Female & $3.42 \pm 0.32$ & \\
\hline & \multirow[t]{2}{*}{ Left ear } & \multirow[t]{2}{*}{$45^{\circ} \mathrm{Left}$} & Male & $3.53 \pm 0.40$ & $0.014 *$ \\
\hline & & & Female & $3.45 \pm 0.35$ & \\
\hline & Right ear & $45^{\circ} \mathrm{Left}$ & Male & $3.56 \pm 0.40$ & $0.006^{*}$ \\
\hline
\end{tabular}




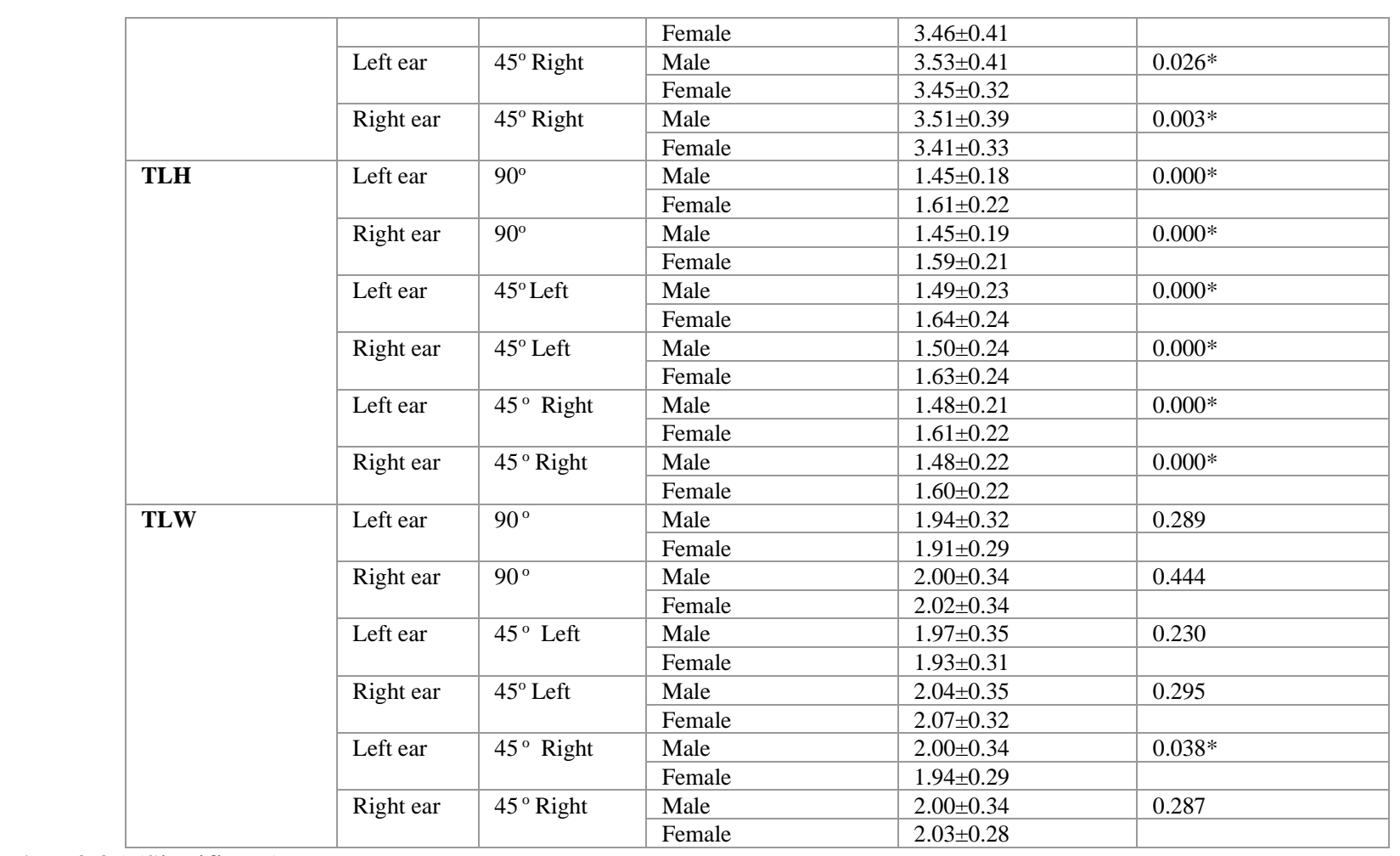

\section{$* \mathrm{P}<0.05$ (Significant)}

Data was analyzed using the t- test for independent samples between sex on both sides (see Table2). It was observed that there is significant difference in the different morphometric parameters of ears in relation to sex $(\mathrm{P}<0.05)$, males had higher TEL, TEW ear parameters than females at all angles, Females were also observed to have a longer TLH than males at $90^{\circ}, 45^{\circ}$ left and $45^{\circ}$ right for both sides of the ear $(\mathrm{P}<0.05)$.

TLW mean length values of the left ear at $90^{\circ}, 45^{\circ}$ left and $45^{\circ}$ right of males are higher than that of females while TLW mean length values of the right ear at $90^{\circ}, 45^{\circ}$ left and $45^{\circ}$ right of females are higher than that of males.

Table 3. Descriptive Statistics Of Auricular Indices Across Cohort In Relation To Sex

\begin{tabular}{|c|c|c|c|c|c|c|c|c|}
\hline \multirow[t]{2}{*}{ Indices } & \multirow[t]{2}{*}{ Angle } & \multirow[t]{2}{*}{ Side } & \multicolumn{2}{|l|}{ Male $(n=258)$} & \multicolumn{2}{|c|}{ Female $(n=256)$} & \multicolumn{2}{|c|}{ Combined $(n=514)$} \\
\hline & & & Mean \pm SD & P-value & Mean \pm SD & P-value & Mean \pm SD & P-value \\
\hline \multirow{6}{*}{$\begin{array}{l}\text { Ear } \\
\text { index }\end{array}$} & \multirow[t]{2}{*}{$90^{\circ}$} & Left ear & $58.49 \pm 6.04$ & \multirow[t]{2}{*}{0.600} & $58.68 \pm 5.76$ & \multirow[t]{2}{*}{0.717} & $58.58 \pm 5.90$ & \multirow[t]{2}{*}{0.878} \\
\hline & & Right ear & $58.68 \pm 6.47$ & & $58.55 \pm 5.16$ & & $58.62 \pm 5.85$ & \\
\hline & \multirow[t]{2}{*}{$45^{\circ} \mathrm{Left}$} & Left ear & $57.68 \pm 6.22$ & \multirow[t]{2}{*}{0.122} & $58.20 \pm 5.65$ & \multirow[t]{2}{*}{0.161} & $57.94 \pm 5.94$ & \multirow[t]{2}{*}{0.850} \\
\hline & & Right ear & $58.22 \pm 6.44$ & & $57.75 \pm 5.86$ & & $57.99 \pm 6.15$ & \\
\hline & \multirow[t]{2}{*}{$45^{\circ}$ Right } & Left ear & $58.22 \pm 6.31$ & \multirow[t]{2}{*}{0.684} & $58.09 \pm 5.80$ & \multirow[t]{2}{*}{$0.011 *$} & $58.16 \pm 6.06$ & \multirow[t]{2}{*}{$0.040^{*}$} \\
\hline & & Right ear & $58.38 \pm 6.55$ & & $58.90 \pm 5.31$ & & $58.64 \pm 5.96$ & \\
\hline \multirow{6}{*}{$\begin{array}{l}\text { Lobule } \\
\text { index }\end{array}$} & \multirow[t]{2}{*}{$90^{\circ}$} & Left ear & $136.05 \pm 26.35$ & \multirow[t]{2}{*}{$0.023 *$} & $120.71 \pm 22.58$ & \multirow[t]{2}{*}{$0.000 *$} & $128.41 \pm 25.69$ & \multirow[t]{2}{*}{$0.000 *$} \\
\hline & & Right ear & $140.04 \pm 26.20$ & & $129.10 \pm 24.23$ & & $134.59 \pm 25.80$ & \\
\hline & \multirow[t]{2}{*}{$45^{\circ} \mathrm{Left}$} & Left ear & $134.10 \pm 27.10$ & \multirow[t]{2}{*}{$0.011 *$} & $119.76 \pm 21.66$ & \multirow[t]{2}{*}{$0.000 *$} & $126.96 \pm 25.55$ & \multirow[t]{2}{*}{$0.000 *$} \\
\hline & & Right ear & $138.38 \pm 28.60$ & & $128.52 \pm 20.96$ & & $133.47 \pm 25.54$ & \\
\hline & \multirow[t]{2}{*}{$45^{\circ}$ Right } & Left ear & $136.61 \pm 27.77$ & \multirow[t]{2}{*}{0.648} & $121.88 \pm 20.93$ & \multirow[t]{2}{*}{$0.001 *$} & $129.27 \pm 25.66$ & \multirow[t]{2}{*}{$0.001 *$} \\
\hline & & Right ear & $137.31 \pm 27.21$ & & $128.56 \pm 21.95$ & & $132.95 \pm 25.10$ & \\
\hline
\end{tabular}

$* \mathrm{P}<0.05$ (Significant) 
Data was analyzed using paired sample/dependent t-test. Table 3 depicts descriptive statistics of different auricular indices in male and female subgroup. Data was analyzed using paired sample/dependent t-test. Significant difference was observed in most of the lobule indices of the left and right ears $(\mathrm{P}<0.05)$. It was also observed that the right lobule indices of both males and females was higher than the left at all angles observed.

Table 4. Different Anthropometric Parameters In Relation To Sex

\begin{tabular}{|c|c|c|c|c|}
\hline Parameter & Sex & Range & Mean \pm SD & P-value \\
\hline \multirow[t]{3}{*}{ Age (years) } & Male & $16-30$ & $22.07 \pm 2.71$ & \multirow[t]{3}{*}{0.466} \\
\hline & Female & $16-30$ & $21.90 \pm 2.73$ & \\
\hline & Total & $16-30$ & $21.99 \pm 2.72$ & \\
\hline \multirow[t]{3}{*}{ Height (m) } & Male & $1.52-1.94$ & $1.73 \pm 0.07$ & \multirow[t]{3}{*}{$0.000^{*}$} \\
\hline & Female & $1.44-1.82$ & $1.64 \pm 0.07$ & \\
\hline & Total & $1.44-1.94$ & $1.69 \pm 0.08$ & \\
\hline \multirow[t]{3}{*}{ Weight (kg) } & Male & $45-100$ & $69.92 \pm 9.31$ & \multirow[t]{3}{*}{$0.000 *$} \\
\hline & Female & $42-100$ & $63.44 \pm 11.13$ & \\
\hline & Total & $42-100$ & $65.69 \pm 10.49$ & \\
\hline
\end{tabular}

$* \mathrm{P}<0.05$ (Significant)

Results from the data (Age, Height and Weight) in relation to sex showed that there is no significant difference in the age of male and female subjects used in this study $(\mathrm{P}>0.05)$ (see Table 4).
This implies that the age distribution of the male and female are relatively uniform. However, there is significant difference in the height and weight of the study subjects in relation to their sex $(\mathrm{P}<0.05)$. This implies that the male is taller and equally heavier than the female subjects.

Table 5. Auricular Anthropometric Parameters at Different Angles

\begin{tabular}{|c|c|c|c|c|}
\hline Parameter & Side & Angle & Mean \pm SD & P-value \\
\hline \multirow[t]{4}{*}{ TEL } & \multirow[t]{2}{*}{ Left ear } & $90^{\circ}$ & $5.91 \pm 0.49$ & \multirow[t]{2}{*}{$0.000 *$} \\
\hline & & $45^{\circ}$ Left & $6.04 \pm 0.55$ & \\
\hline & \multirow{2}{*}{ Right ear } & $90^{\circ}$ & $5.91 \pm 0.50$ & \multirow[t]{2}{*}{$0.000 *$} \\
\hline & & $45^{\circ}$ Left & $6.08 \pm 0.57$ & \\
\hline \multirow[t]{4}{*}{ TEW } & \multirow[t]{2}{*}{ Left ear } & $90^{\circ}$ & $3.45 \pm 0.35$ & \multirow[t]{2}{*}{$0.012 *$} \\
\hline & & $45^{\circ}$ Left & $3.49 \pm 0.38$ & \\
\hline & \multirow[t]{2}{*}{ Right ear } & $90^{\circ}$ & $3.46 \pm 0.36$ & \multirow[t]{2}{*}{$0.011 *$} \\
\hline & & $45^{\circ}$ Left & $3.51 \pm 0.41$ & \\
\hline \multirow[t]{4}{*}{ TLH } & \multirow[t]{2}{*}{ Left ear } & $90^{\circ}$ & $1.52 \pm 0.22$ & \multirow[t]{2}{*}{0.000} \\
\hline & & $45^{\circ}$ Left & $1.56 \pm 0.25$ & \\
\hline & \multirow[t]{2}{*}{ Right ear } & $90^{\circ}$ & $1.53 \pm 0.22$ & \multirow[t]{2}{*}{$0.000^{*}$} \\
\hline & & $45^{\circ}$ Left & $1.57 \pm 0.25$ & \\
\hline \multirow[t]{2}{*}{ TLW } & Left ear & $90^{\circ}$ & $1.93 \pm 0.31$ & $0.018^{*}$ \\
\hline & & $45^{\circ}$ Left & $1.95 \pm 0.33$ & $0.016^{*}$ \\
\hline
\end{tabular}




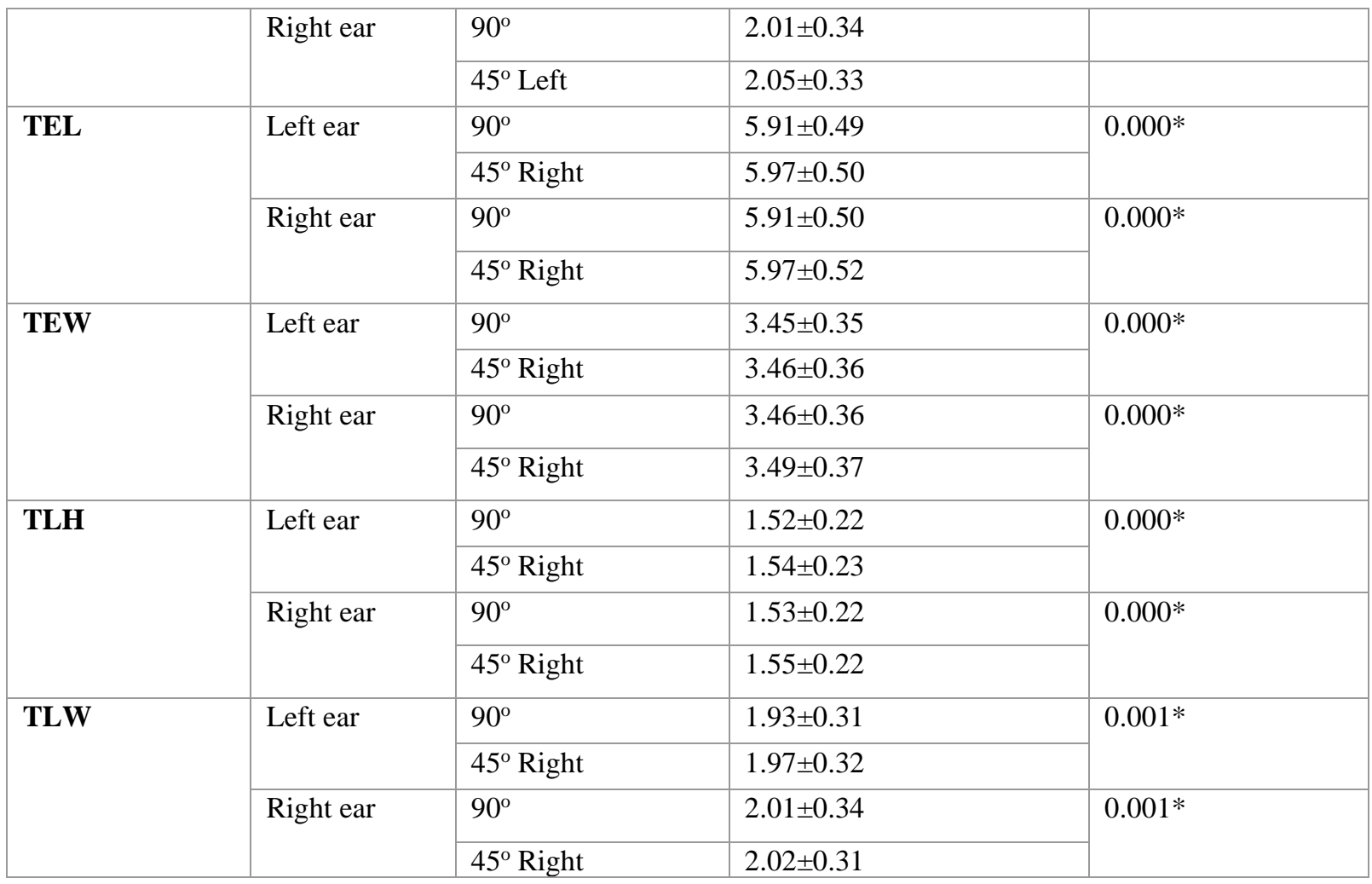

Table 6. Regression Formula of Predicting Measurement of $90^{\circ}$ from the Measurements of $45^{\circ}$ of Both Ears are as Follows

\begin{tabular}{|c|c|c|c|c|c|}
\hline Left ear: & TEL & $=$ & 1.642 & + & $0.707\left(45^{\circ}\right.$ Left $)$ \\
\hline & & $=$ & 0.826 & + & $0.852\left(45^{\circ}\right.$ Right $)$ \\
\hline \multirow[t]{2}{*}{ Right ear: } & TEL & $=$ & 2.166 & + & $0.616\left(45^{\circ}\right.$ Left $)$ \\
\hline & & $=$ & 2.128 & + & $0.774\left(45^{\circ}\right.$ Right $)$ \\
\hline \multirow[t]{2}{*}{ Left ear: } & TEW & $=$ & 1.308 & + & $0.615\left(45^{\circ}\right.$ Left $)$ \\
\hline & & $=$ & 1.133 & + & $0.665\left(45^{\circ}\right.$ Right $)$ \\
\hline \multirow[t]{2}{*}{ Right ear: } & TEW & $=$ & 1.417 & + & $0.580\left(45^{\circ}\right.$ Left $)$ \\
\hline & & $=$ & 1.191 & + & $0.654\left(45^{\circ}\right.$ Right $)$ \\
\hline \multirow[t]{2}{*}{ Left ear: } & TLH & $=$ & 0.364 & + & $0.744\left(45^{\circ}\right.$ Left $)$ \\
\hline & & $=$ & 0.233 & + & $0.837\left(45^{\circ}\right.$ Right $)$ \\
\hline \multirow[t]{2}{*}{ Right ear: } & TLH & $=$ & 0.434 & + & $0.691\left(45^{\circ}\right.$ Left $)$ \\
\hline & & $=$ & 0.309 & + & $0.783\left(45^{\circ}\right.$ Right $)$ \\
\hline \multirow[t]{2}{*}{ Left ear: } & TLW & $=$ & 0.486 & + & $0.740\left(45^{\circ}\right.$ Left $)$ \\
\hline & & $=$ & 0.473 & + & $0.740\left(45^{\circ}\right.$ Right $)$ \\
\hline \multirow[t]{2}{*}{ Right ear: } & TLW & $=$ & 0.573 & + & $0.701\left(45^{\circ}\right.$ Left $)$ \\
\hline & & $=$ & 0.380 & + & $0.810\left(45^{\circ}\right.$ Right $)$ \\
\hline
\end{tabular}




\section{Discussion}

Total Ear Length results from this study (see Table 2) shows significant difference in the different auricular morphometric parameters in relation to sex $\mathrm{P}<0.05$, TEL was significantly higher in males compared to females at all angles measured. This is supportive of the fact that auricular dimensions exhibit sexual dimorphism and differences between sexes are statistically significant with higher values in males due to auricular expansion which occurs earlier in males compared to females and continues till it attains maturity as stipulated by [13].

Adult males under the influence of testosterone have a significant increase in bone growth and twice the number of muscle cells of the average female [14]. This corroborates with the findings of this study (see Table 4), where significant difference in height and weight of our cohort was observed in relation to their sex $(\mathrm{P}<0.05)$. This implies that the male subjects are taller and heavier than the females.

Total Ear Width Sexual dimorphism was observed in our present study (see Table 2) with the males having significantly higher TEW values than females at all angles $\left(90^{0} 45^{\circ}\right.$ left and $45^{\circ}$ right of both ears) $(\mathrm{P}<0.05)$. These findings concur with the findings of [15], [16], [11], [8], [17], [5], [8], [18].

Total Lobule Height in this study, significant difference in TLH in relation to sex $(\mathrm{P}<0.05)$ (see Table 2$)$ was also observed. This implies that females have a longer TLH than males at $90^{\circ}, 45^{\circ}$ left and $45^{\circ}$ right of both ears which is in agreement with the study of [8], [17], [19], [20], who reported that the changes in size of lobule are mainly seen due to gravitational forces secondary to wearing of ornaments, earrings by females which impose additional weight on the ears, therefore further increasing ear length. However, some studies by [16], [15], [11] reported higher male mean LH. These differences could be specific to the geographical locations, environment, ethnic group, genetics, and ornamental inclinations of the male and female subjects employed in their studies.

Total Lobule Width Several studies on the variations of the external ear have shown that both ears of an individual vary in its dimensions. These structural differences in the human ear create unique shapes and morphology [20].

In this study, both males and females were observed to have higher mean values on the right side than on the left. Sexual dimorphism was also noticed in Table 2 of this study where TLW mean values at $90^{\circ}, 45^{\circ}$ left and $45^{\circ}$ right were higher in left ear of male subjects than the females left lobule width. This has a close match with the findings of [15], [7], [8] who reported higher mean Lobule Width observations in males than females.

Auricular and Lobule Indices: Ferrario, [4] reported that "differences between the left and right parts of the human face, especially differences between the paired structures, are well known in healthy people.

In this study, right lobule index of males and females was found to be statistically higher $(P<0.05)$ compared to the left (see Table 3). This was similar to the findings of [15], [11], who reported that all parameters measured in their study were significantly larger and statistically significant on right side in both males and females. The comparison of different anthropometric parameters in relation to ear side using paired sample t-test showed that TLW is significant at $90^{\circ}, 45^{\circ}$ left, and $45^{\circ}$ right $(\mathrm{P}<0.05)$, the ear height was also significant at $45^{\circ}$ left $(\mathrm{P}<0.05)$. This implies that the lobule is wider at the right ear than the left ear, and the ear is longer at the right than the left side (see Table 5).

Regression equation for predicting measurements of $90^{\circ}$ from the $45^{\circ}$ measurements of TEL and TEW (see Table 6) was also derived in this present study to help match current security challenges and serve as a valuable additional identification tool for faces captured in arbitrary pose from surveillance equipment( camera`s).It can also give room for proper conversion intervention in a situation where only the side view of pictures of the auricle is gotten at varying angles other than $90^{\circ}$. Therefore, in this regards the use of the generated formula which is specific to the Igbo ethnic group can be a valuable amendment to existing facial recognition systems for identifying subjects.

\section{Conclusion}

Findings from this study can aid identification of individuals, facial recognition from security cameras, planning of cosmetic surgery and product design for specific consumer auricular requirements.

\section{Recommendation}

This study has shown that ear is a structure variable enough to be considered useful for the purpose of forensic identification, It is hence recommended that further studies should be carried out using larger population, Age range should be increased and selection of individual tribes for wider anthropometric coverage in Nigeria and Africa.

\section{References}

[1] Douglas, T. S., (2004). Image processing for craniofacial landmark identification and measurement: a review of photogrammetry and cephalometry. Comput MedImaging Graph. 28(7):401-9.

[2] Pflug, A., (2015). "Ear Recognition Biometric Identification using 2- and 3-Dimensional Images of Human Ears(PhD Thesis) Gjøvik University College.

[3] Feenstra, L. and van der Lugt, C., (2000). Ear witness. The journal of laryngology otology.114;497-500.

[4] Ferrario, V. F., Sforza C, Ciusa V, Serro G, Tartaglia GM., (1999) 'Morphometry Of The Normal Human Ear: A CrossSectional Study From Adolescence To Mid-Adulthood', Journal of Craniofacial Genetics and Developmental Biology, 19(4), pp. 226-233

[5] Akpa, A.O.C., Ama, A. Ibiam, Chukwuebuka Ugwu, (2013). Anthropometrical Study Of The Pinna Among Southeast Nigerians. Journal Of Experimental Research. 134(1), Pp. 9-23 
[6] Pechinkina, E.A benfer, R.A.J., Vershoubskaya, G.G., and Kozlov A.I., (2000). Genetic and environmental influence on the asymmetry of dermatoglyphic traits. American journal of physical anthropology. 111(4): 531-543.

[7] Ekanem, A., Garba, S., Musa, S., et al. Anthropometric study of the Pinna (Auricle) among adult Nigerians resident in Maiduguri metropolis. J of Med Sci. 2010; 10:176-80.

[8] Eboh, D., (2013). Morphological Changes Of The Human Pinna In Relation To Age And Gender Of Urhobo People In Southern Nigeria. Journal of Experimental clinical anatomy: 37(6): pp 605-16.

[9] Piquero, A., Brame, R., Mazerolle, P., and Haapanen, R., (2002). Crime in Emerging Adulthood. Criminology 40: 137-69.

[10] World Medical Association Declaration of Helsinki. (2008). Ethical Principles for Medical Research Involving Human Subjects Internet]. Available from: http://www.net/en/30publication/10polocies/b3/index.html.

[Access Date:13 May 2020].

[11] Singhal J., Sharma N., Jain S.K., Budhiraja V., Rastogi R., Garg R., Nafees H., (2016;). A Study of Auricle Morphology for Identification in Indians. Annals of International Medical and Dental Research. 2(4):217-247.

[12] Nathan, N., K. Latham, J. Cooper, C. Perlyn, I. Gozlan and S.R. Thaller, (2008). Anthropometry of the external ear in children with cleft lip and palate in comparison to age-matched controls. J. Craniofac. Surg., 19: 1391-1395.

[13] Taura, M.G., Adamu, L.H., Modibbo, (2013). MH. External ear anthropometry among hausas of Nigeria; the search of sexual dimorphism and correlations. WSRJ; 1:91-5.

[14] Cheek, D. B., (1974). Body Composition, Hormones, Nutrition And Adolescent Growth, In:Grumbach M. M, Grave G.D Mayer F.E, eds. Control of the onset of puberty New York John Wiley and Sons :424-47.

[15] Shireen, S. and Karadkhelkar, V. P. (2015) 'Anthropometric Measurements of Human External Ear.', Journal of Evolution of Medical and Dental Sciences-Jemds, 4(59), pp. 10333-10338. doi: $10.14260 /$ jemds/2015/1489.

[16] Kalra, D., Kalra, A., Goel, S., (2015). Anthrometric Measurements Of External Ear: An In Vivo Study. International Journal of Enhanced Research in Medicine and Dental Care.;25(3): pp 10-6

[17] Sharma, A., Sidhu, N. K., Sharma, M.K., Kapoor, K., Singh, B., (2007). 'Morphometric Study Of Ear Lobule In Northwest Indian Male Subjects', Anatomical Science International, 82(2), pp. 98-104. 1-110.e7 doi: 10.1111/j.1447-073X.2007.00166.x.

[18] Ewunonu, E.O., and Anibeze, C.I.P., (2013). Anthropometric Study Of The Facial Morphology In A South Eastern Nigerian Population. Human biology review 2(4),314-323.

[19] Kearney, B., Henneberg, M., (2003). Variations of the external ear in an Australian population for the purposes of identification author: (BSC Thesis)university of Adelaide.
[20] Barut, C., Aktune A., (2006). Anthropometric Measurement of the external ear in a group of Turkish Primary School Students. Aesth Plast Surg; 30:225-59. 